\title{
ANALISIS STRES KERJA AKIBAT BEBAN KERJA MENTAL PADA PEKERJA PT. KERTA RAJASA RAYA
}

\author{
Hanif Rizqi Diniari \\ Departemen Keselamatan dan Kesehatan Kerja, \\ Fakultas Kesehatan Masyarakat, Universitas Airlangga \\ Email: hanifrizqi@gmail.com
}

\begin{abstract}
Workers' workload in the work place can cause the difference of work performance. One of the effects is job stress on the workers. Job stress can caused by workload factor in the work place, one of the workloads is mental workload. The purpose of this research was to analyze job stress on workers in PT. Kerta Rajasa Raya. This research was an observational descriptive research, using cross sectional approach. The sample of this research was 47 morning shift-workers in Circulator Loom Unit PT. Kerta Rajasa Raya. The technique of collecting sample was total sampling method. The collected data was mental workload assessment that use NASA-TLX questionnaire, fulfillment of job stress measurement that use questionnaire which adopted from International Stress Management Association (ISMA). Data analysis was using Spearman Correlation test. The result of the research shown that most workers has mental workload with medium category $(53,2 \%)$ and job stress with medium category (76,6\%). Correlation coefficient ( $r$ ) between mental workload and job stress is 0,186. This shows that there was a very weak correlation between mental workload and job stress on workers in PT. Kerta Rajasa Raya. Based on this data, it can be concluded that mental workload is not factor that caused job stress. It is suggested for the related company to do some efforts to reduce the level of job stress by holding a routine exercise and recreation to the workers. Beside that, it is suggested to make a job rotation to the workers.
\end{abstract}

Keywords: Job Stress, Mental Workload

\begin{abstract}
ABSTRAK
Beban kerja yang didapat pekerja di tempat kerja dapat mempengaruhi performa kerja. Salah satu efek turunnya performa kerja yaitu terjadinya stres kerja yang dialami pekerja. Stres kerja dapat terjadi karena adanya faktor beban kerja di tempat kerja, salah satunya yaitu beban kerja mental. Penelitian ini bertujuan untuk menganalisis stres kerja akibat beban kerja mental pada pekerja PT. Kerta Rajasa Raya. Penelitian ini merupakan penelitian observasional deskriptif, menggunakan desain penelitian cross sectional. Sampel penelitian sebesar 47 orang yang merupakan seluruh pekerja shift pagi pada Unit Circulator Loom PT. Kerta Rajasa Raya. Cara pengambilan sampel pada penelitian ini adalah total populasi. Pengumpulan data meliputi penilaian beban kerja mental dengan pengisian kuesioner NASA-TLX, pengisian kuesioner pengukuran stres kerja dengan menggunakan kuesioner yang diadopsi dari International Stress Management Association (ISMA). Analisis data yang digunakan dalam penelitian ini adalah uji korelasi Spearman. Hasil penelitian menunjukkan sebagian besar pekerja memiliki beban kerja mental sedang $(53,2 \%)$ dan mengalami stres kerja kategori sedang $(76,6 \%)$. Nilai koefisien korelasi (r) antara beban kerja mental dengan stres kerja sebesar 0,186 . Hal ini menunjukkan adanya hubungan
\end{abstract}


yang sangat lemah antara beban kerja mental dengan stres kerja pada pekerja PT. Kerta Rajasa Raya. Kesimpulan dari penelitian ini adalah beban kerja mental tidak menjadi faktor yang menyebabkan terjadinya stres kerja. Sebaiknya perlu dilakukan upaya untuk mengurangi stres kerja yang dialami pekerja dengan cara mengadakan kegiatan olahraga dan rekreasi bersama secara berkala oleh pihak perusahaan serta melakukan rotasi kerja pada pekerja.

Kata kunci: Stres Kerja, Beban Kerja Mental

\section{PENDAHULUAN}

Penggunaan teknologi yang maju sangat diperlukan untuk pemenuhan kebutuhan hidup manusia secara luas. Penggunaan kemajuan teknologi ini tidak dapat dihindari, terutama pada era indus-trialisasi saat ini yang ditandai dengan adanya proses mekanisasi, elektrifikasi, modernisasi dan transformasi globalisasi. Penggunaan alat dan bahan tersebut selain memberikan kemudahan bagi suatu proses produksi, tentunya efek samping yang tidak dapat dihindari adalah bertambahnya jumlah dan jenis sumber bahaya bagi pengguna teknologi itu sendiri. Jika efek tersebut tidak disertai dengan pengendalian yang tepat, maka akan dapat merugikan manusia itu sendiri. Selain itu, faktor lingkungan kerja yang tidak memenuhi syarat Keselamatan dan Kesehatan Kerja (K3), proses kerja yang tidak aman dan sistem kerja yang semakin komplek dan modern dapat menjadi ancaman tersendiri bagi keselamatan dan kesehatan pekerja. ${ }^{1}$

Keseimbangan kerja yang menguntungkan dari beberapa faktor, yaitu beban kerja, beban tambahan pada lingkungan kerja dan kapasitas kerja diperlukan agar seorang pekerja berada dalam keserasian kerja yang baik dan dapat terjamin keadaan kesehatan dan produktivitas kerja maksimal. $^{2}$

Hasil penelitian Labour Force Survey pada tahun 1990 menemukan adanya 182.700 kasus stres akibat kerja di Inggris dan yang menjadi sumber penyebabnya tidak hanya karena pekerjaan itu sendiri, tetapi dapat juga karena adanya stresor fisik, emosional dan mental. $^{3}$

Menurut konsep keseimbangan ergonomi, beban kerja baik fisik maupun mental dengan kemampuan fisik, kognitif dan keterbatasan manusia yang menerima beban kerja tersebut harus seimbang. Beban kerja yang terlalu tinggi dapat mengakibatkan overstress dan beban kerja yang terlalu rendah dapat mengakibatkan understress. Selain itu, stres kerja juga akan mengganggu performa kerja dan meningkatkan risiko terjadinya kecelakaan kerja. Secara khusus, stres kerja akan menurunkan produktivitas kerja dan menyebabkan biaya kompensasi pekerja mengalami peningkatan. ${ }^{4}$

Faktor beban kerja di tempat kerja dapat mempengaruhi dapat mempengaruhi performa kerja. Beban kerja yang dialami dapat berupa beban kerja mental. ${ }^{4}$ Beban kerja berlebih dapat menurunkan performa kerja dan mengakibatkan 
timbulnya stres. Tujuan dari penelitian ini adalah untuk menganalisis stres kerja akibat beban kerja mental pada pekerja di PT. Kerta Rajasa Raya.

\section{METODE PENELITIAN}

Penelitian ini merupakan penelitian observasional deskriptif, menggunakan desain penelitian cross sectional. Sampel penelitian sebesar 47 orang yang merupakan seluruh pekerja shift pagi pada Unit Circulator Loom PT. Kerta Rajasa Raya. Cara pengambilan sampel pada penelitian ini adalah total populasi.

Variabel pada penelitian ini adalah beban kerja mental pekerja PT. Kerta Rajasa Raya sebagai variabel independen dan stres kerja yang dialami pekerja sebagai variabel dependen. Instrumen yang digunakan pada penelitian ini untuk mendapatkan data primer diperoleh melalui pengisian kuesioner oleh responden. Pengumpulan data tersebut meliputi penilaian beban kerja mental dengan pengisian kuesioner NASA-TLX, pengisian kuesioner pengukuran stres kerja dengan menggunakan kuesioner yang diadopsi dari International Stress Management Association (ISMA). Analisis data yang digunakan dalam penelitian ini adalah uji korelasi Spearman.

\section{HASIL DAN PEMBAHASAN}

Data umum pada penelitian ini didasarkan pada karakteristik pekerja. Karakteristik pekerja pada penelitian ini dilihat menurut umur pekerja di PT. Kerta Rajasa Raya. Karakteristik pekerja berda-sarkan umur diketahui bahwa data umur pekerja di Unit Circulator Loom PT. Kerta Rajasa Raya yaitu umur termuda adalah 34 tahun dan umur tertua adalah 60 tahun. Rentang umur pekerja di Unit Circulator Loom PT. Kerta Rajasa Raya dibagi menjadi 6 (enam) kelas atau kategori dengan jumlah interval 4. Karakteristik pekerja berdasarkan umur pada pekerja PT. Kerta Rajasa Raya ditampilkan pada Tabel 1.

Tabel 1. Karakteristik Pekerja Berdasarkan Umur pada pekerja PT. Kerta Rajasa Raya

\begin{tabular}{lccr}
\hline No & Umur & $\mathrm{n}$ & Persentase $(\%)$ \\
\hline 1. & $34-38$ & 12 & 25,50 \\
2. & $39-43$ & 12 & 25,50 \\
3. & $44-48$ & 11 & 23,40 \\
4. & $49-53$ & 8 & 17,00 \\
5. & $54-58$ & 3 & 6,40 \\
6. & $59-63$ & 1 & 2,10 \\
\hline \multicolumn{2}{l}{ Total } & 47 & 100,00 \\
\hline
\end{tabular}

Berdasarkan Tabel 1 di atas, diketahui bahwa umur pekerja di Unit Circulator Loom PT. Kerta Rajasa Raya paling banyak adalah umur 34-38 tahun dan 39-43 tahun, yaitu masing-masing sebanyak 12 orang atau sebesar $25,5 \%$ dari jumlah keseluruhan.

Data khusus pada penelitian ini meliputi beban kerja mental, stres kerja dan analisis stres kerja akibat beban kerja mental.

\section{a. Beban Kerja Mental}

Beban kerja mental pada pekerja PT. Kerta Rajasa Raya dikategorikan menjadi 3 
(tiga) kategori, yaitu beban kerja mental ringan, beban kerja mental sedang dan beban kerja mental berat. Hasil penilaian beban kerja mental pekerja PT. Kerta Rajasa Raya ditampilkan pada Tabel 2.

Tabel 2. Hasil Penilaian Beban Kerja Mental pada Pekerja PT. Kerta Rajasa Raya

\begin{tabular}{llcr}
\hline No & $\begin{array}{c}\text { Beban Kerja } \\
\text { Mental }\end{array}$ & n & Persentase (\%) \\
\hline 1. & Ringan & 6 & 12,80 \\
2. & Sedang & 25 & 53,20 \\
3. $\quad$ Berat & 16 & 34,00 \\
\hline \multicolumn{2}{l}{ Total } & 47 & 100,00 \\
\hline
\end{tabular}

Berdasarkan Tabel 2 di atas, dapat diketahui bahwa mayoritas dari pekerja PT. Kerta Rajasa Raya memiliki beban kerja mental dengan tingkat sedang, yaitu sebanyak 25 pekerja atau sebesar $53,2 \%$ dari jumlah keseluruhan.

Pengukuran beban kerja mental pada pekerja PT. Kerta Rajasa Raya dilakukan dengan pengisian kuesioner NASA-TLX oleh pekerja. Kuesioner disusun berdasarkan 6 (enam) dimensi pengukuran beban kerja mental, yaitu Mental Demand (MD), Physical Demand (PD), Temporal Demand (TD), Own Performance (OP), Effort (EF) dan Frustation (FR). Hasil penilaian beban kerja mental menunjukkan bahwa mayoritas dari pekerja PT. Kerta Rajasa Raya memiliki beban kerja mental dengan tingkat sedang.

Hasil penilaian beban kerja mental menunjukkan bahwa dimensi pengukuran beban kerja mental yang paling tinggi adalah Effort (EF) dan Physical Demand (PD). Effort (EF) merupakan dimensi pengukuran pertama yang paling mempengaruhi beban kerja mental. Pekerja PT. Kerta Rajasa Raya mengeluarkan usaha yang maksimal dalam menyelesaikan pekerjaannya, baik fisik maupun mental. Contohnya seperti mengirimkan benang shuttle pada setiap mesin yang membutuhkan dengan menggunakan handjack yang ditarik secara manual. Setiap pekerja selalu berusaha maksimal dalam setiap aktivitas kerja yang dilakukan. Setelah itu, dimensi pengukuran kedua yang dominan, yaitu Physical Demand (PD). Pekerja melakukan banyak aktivitas fisik secara manual seperti menarik handjack yang berisi keranjang benang shuttle, mengganti benang shuttle pada mesin dan melakukan perbaikan pada mesin yang rusak. Aktivitas tersebut dilakukan secara terus - menerus selama bekerja.

Beban tugas yang bersifat mental dan tanggung jawab dari suatu pekerjaan lebih memberikan stres yang tinggi dibandingkan dengan beban kerja fisik. ${ }^{5}$ Hal ini juga diperkuat oleh Winarsunu (2008) yang mengungkapkan bahwa pekerja yang merasa tidak mampu menanggung beban kerja mental karena melebihi kapasitasnya akan mengalami stres kerja. $^{6}$ Prinsip ergonomi menjelaskan bagaimana task demand sama dengan work capacity pekerja sehingga diperlukan agar beban kerja mental yang diterima oleh tubuh 
pekerja tidak melebihi atau sama dengan kapasitas mental pekerja tersebut. Teori tersebut juga didukung oleh hasil penelitian yang dilakukan oleh Fahamsyah (2017) yang menyatakan bahwa adanya hubungan antara beban kerja mental dengan kejadian stres kerja pada pekerja. $^{7}$

\section{b. Stres Kerja}

Stres kerja pada pekerja PT. Kerta Rajasa Raya dikategorikan menjadi 3 (tiga) kategori, yaitu stres kerja ringan, stres kerja sedang dan stres kerja berat. Hasil pengukuran stres kerja pekerja PT. Kerta Rajasa Raya ditampilkan pada Tabel 3.

Tabel 3. Hasil Pengukuran Stres Kerja pada Pekerja PT. Kerta Rajasa Raya

\begin{tabular}{llcr}
\hline No. & Stres Kerja & $\mathrm{n}$ & Persentase $(\%)$ \\
\hline 1. & Stres ringan & 5 & 10,60 \\
2. & Stres sedang & 36 & 76,60 \\
3. & Stres berat & 6 & 12,80 \\
\hline Total & & 47 & 100,00 \\
\hline
\end{tabular}

Berdasarkan Tabel 3 di atas, diketahui bahwa sebagian besar pekerja PT. Kerta Rajasa Raya mengalami stres kerja sedang, yaitu sebanyak 36 pekerja atau sebesar 76,6\% dari jumlah keseluruhan.

Stres kerja merupakan reaksi pada tubuh manusia berupa reaksi fisiologis maupun psikologis maupun perilaku akibat stresor yang dialami di tempat kerja. Berdasarkan hasil penelitian, diketahui bahwa sebagian besar pekerja PT. Kerta Rajasa Raya mengalami stres kerja sedang, yaitu sebanyak 36 pekerja atau sebesar 76,6\% dari jumlah keseluruhan.

Dampak stres kerja yang dialami pekerja tidak hanya berpengaruh pada pekerja yang mengalami namun juga berpengaruh pada tingkat organisasi, yaitu pada tempat kerja atau perusahaan. Dampak terhadap individu dapat berupa dampak subjektif, seperti kekhawatiran, ketakutan, apatis, rasa bosan, depresi, keletihan, frustasi, kehilangan kendali emosi dan gugup. Selain itu, dampak lain yang dapat terjadi adalah dampak perilaku berupa mudah mendapat kecelakaan, kecanduan alkohol, penyalahgunaan obat, luapan emosional serta makan atau merokok secara berlebihan. Pada tingkat organisasi, stres kerja dapat berdampak pada angka absensi, omset perusahaan, produktivitas kerja rendah, asing dengan mitra kerja, komitmen organisasi dan loyalitas berkurang. ${ }^{8}$

Pengendalian stres kerja dapat dikelola dengan manajemen stres. Manajemen stres ini meliputi pendekatan pribadi dan pendekatan organisasi. Pendekatan pribadi dilakukan pada pekerja dengan melakukan strategi psikologis dan strategi fisiologis, sedangkan pendekatan organisasi dapat dilakukan dengan cara meningkatkan komunikasi, sistem penilaian dan imbalan yang efektif, meningkatkan partisipasi, memperkaya tugas dan mengembangkan keterampilan, kepribadian dan pekerjaan. ${ }^{8}$

Hasil penelitian Prabowo (2010) di bagian produksi industri mebel PT. Chia Jiann 
Indonesia Furniture menyatakan bahwa sebagian besar responden juga mengalami stres kerja sedang, yaitu sebesar $76 \%$. Berdasarkan penelitian tersebut diketahui bahwa terdapat beberapa faktor yang mempengaruhi stres kerja, yaitu masa kerja dan beban kerja. ${ }^{9}$

\section{c. Analisis Stres Kerja akibat Beban Kerja}

\section{Mental}

Hasil tabulasi silang antara beban kerja mental dan stres kerja ditampilkan pada Tabel 4.

Tabel 4. Tabulasi Silang antara Beban Kerja Mental dan Stres Kerja pada Pekerja PT. Kerta Rajasa Raya

\begin{tabular}{|c|c|c|c|c|c|c|c|c|}
\hline \multirow{3}{*}{ Beban Kerja Mental } & \multicolumn{6}{|c|}{ Stres Kerja } & \multirow{2}{*}{\multicolumn{2}{|c|}{ Total }} \\
\hline & \multicolumn{2}{|c|}{ Ringan } & \multicolumn{2}{|c|}{ Sedang } & \multicolumn{2}{|c|}{ Berat } & & \\
\hline & $\mathrm{n}$ & $\%$ & $\mathrm{n}$ & $\%$ & $\mathrm{n}$ & $\%$ & $\mathrm{n}$ & $\%$ \\
\hline Ringan & 1 & 16,70 & 5 & 83,30 & 0 & 0,00 & 6 & 100,00 \\
\hline Sedang & 3 & 12,00 & 19 & 76,00 & 3 & 12,00 & 25 & 100,00 \\
\hline Berat & 1 & 6,30 & 12 & 75,00 & 3 & 18,80 & 16 & 100,00 \\
\hline
\end{tabular}

Berdasarkan Tabel 4 di atas, diketahui bahwa secara deskriptif sebanyak 12 pekerja atau $75 \%$ dari pekerja yang memiliki beban kerja mental berat mengalami stres kerja sedang. Kemudian, sebanyak 3 pekerja atau $18,8 \%$ pekerja yang memiliki beban kerja mental berat mengalami stres kerja berat. Kemudian, sebanyak 19 pekerja atau $76 \%$ pekerja yang memiliki beban kerja mental sedang mengalami stres kerja sedang. Berdasarkan hasil uji kekuatan hubungan menggunakan uji korelasi Spearman, didapatkan nilai koefisien korelasi (r) sebesar 0,186 yang menunjukkan adanya hubungan yang sangat lemah antara beban kerja mental dan stres kerja.

Hal ini sejalan dengan penelitian yang dilakukan oleh Fitri (2013) yang mengatakan bahwa tidak ada hubungan antara beban kerja mental dengan stres kerja. ${ }^{10}$ Namun, bertolak belakang dengan penelitian yang dilakukan oleh Amalia, et al. (2017). Hasil penelitian tersebut mengatakan bahwa ada hubungan antara beban kerja mental dengan stres kerja pada guru SLB Negeri Semarang. ${ }^{11}$ Hal tersebut mungkin dikarenakan profesi guru SLB menghadapi kondisi yang lebih melibatkan mental daripada pekerja suatu pabrik, dalam hal ini pekerja PT. Kerta Rajasa Raya, yang bergerak pada bidang produksi karung plastik. Dalam penelitian yang dilakukan Prabawati (2012) dijelaskan bahwa beban kerja mental yang tinggi dapat menyebabkan timbulnya rangsangan pada sistem saraf pusat yang dapat menyebabkan rasa sakit atau penyakit akibat kerja. Bila beban kerja mental melebihi kemampuan tubuh, maka akan terjadi rasa tidak nyaman, kelelahan, cedera serta penurunan produktivitas kerja. ${ }^{12}$ 
Sebagian besar pekerja PT. Kerta Rajasa Raya merasa beban kerja mental yang dimiliki berada pada tingkat sedang dan mengalami stres kerja sedang. Pekerja menganggap bekerja dengan pekerjaannya sekarang telah merasa terbiasa dan berusaha menikmati pekerjaan tersebut.

Beban kerja mental adalah suatu perbedaan antara kapasitas atau kemampuan mental pekerja dengan tuntutan tugas dan pekerjaan yang harus dihadapi. Beban kerja yang tidak optimal merupakan salah satu sumber stres. Beban kerja yang terlalu sedikit akan menyebabkan rasa jenuh dan menimbulkan kebosanan pada pekerja yang menyebabkan terjadinya understress, sedangkan beban kerja yang terlalu tinggi akan menyebabkan pemakaian energi yang berlebihan, sehingga memicu terjadinya kelelahan, baik kelelahan mental maupun kelelahan fisik yang dapat menyebabkan terjadinya overstress. ${ }^{4}$

\section{SIMPULAN DAN SARAN}

\section{Simpulan}

Berdasarkan hasil penelitian tentang analisis stres Kerja akibat beban kerja mental pada pekerja Pt. Kerta Rajasa Raya, maka didapatkan kesimpulan antara lain:

1. Sebagian besar pekerja PT. Kerta Rajasa Raya memiliki beban kerja mental sedang (53,2\%), dengan faktor dominan Effort (EF) dan Physical Demand (PD).
2. Sebagian besar pekerja di Unit Circulator Loom PT. Kerta Rajasa Raya mengalami stres kerja sedang $(76,6 \%)$.

3. Beban kerja mental memiliki hubungan yang sangat lemah dengan terjadinya stres kerja pada pekerja PT. Kerta Rajasa Raya.

\section{Saran}

1. Sebaiknya pekerja tetap dihimbau melakukan istirahat yang cukup untuk menjaga keseimbangan tubuh ketika melakukan aktivitas kerja.

2. Untuk mengurangi tingkat stres kerja, sebaiknya perusahaan mengadakan kegiatan olahraga dan rekreasi bersama secara berkala.

3. Sebaiknya dilakukan penelitian lebih lanjut untuk mengidentifikasi sumber stres lain di tempat kerja.

\section{REFERENSI}

1. Tarwaka, 2008. Keselamatan dan Kesehatan Kerja: Manajemen dan Implementasi K3 di Tempat Kerja. Surakarta: Harapan Press.

2. Suma'mur, 2009. Higiene Perusahaan dan Kesehatan Kerja (Hiperkes). Jakarta: Sagung Seto.

3. Harrianto, R., 2010. Buku Ajar Kesehatan Kerja. Jakarta: Penerbit Buku Kedokteran EGC.

4. Tarwaka, 2013. Ergonomi Industri: DasarDasar Pengetahuan Ergonomi dan Aplikasi di Tempat Kerja. Surakarta: Harapan Press.

5. Wijono, S., 2010. Psikologi Industri dan Organisasi. Jakarta: Fajar Interpratama Offset. 
6. Winarsunu, T., 2008. Psikologi Keselamatan Kerja. Malang: UMM Press.

7. Fahamsyah, D., 2017. Analisis Hubungan Beban Kerja Mental dengan Stres Kerja di Instalasi CSSD Rumah Sakit Umum Haji Surabaya. The Indonesian Journal of Occupational Safety and Health.

8. Septianto, D., 2010. Pengaruh Lingkungan Kerja dan Stres Kerja terhadap Kinerja Karyawan (Studi pada PT. Pataya Raya Semarang). Jurnal Skripsi. Universitas Diponegoro.

9. Prabowo, Y. F., 2010. Faktor yang Berhubungan dengan Kejadian Stres Kerja pada Bagian Produksi Industri Mebel PT. Chia Jiann Indonesia Furniture di Wedelan Jepara Tahun 2009. Skripsi. Universitas Negeri Semarang.

10. Fitri, A. M., 2013. Analisis Faktor - Faktor yang Berhubungan dengan Kejadian Stres Kerja pada Karyawan Bank (Studi pada Karyawan Bank BMT). Jurnal Kesehatan Masyarakat.

11. Amalia, B. R., Ida Wahyuni dan Ekawati. 2017. Hubungan Antara Karakteristik Individu, Beban Kerja Mental, Pengembangan Karir dan Hubungan Interpersonal dengan Stres Kerja pada Guru di SLB Negeri Semarang. Jurnal Kesehatan Masyarakat.

12. Prabawati, R., 2012. Hubungan Beban Kerja Mental dengan Stres Kerja pada Perawat Rawat Inap RSJD Dr. R. M. Soedjarwadi Klaten. Skripsi. Universitas Sebelas Maret. 